\title{
Microbial Safety of Low Water Activity Foods: Study of Simulated and Durban Household Samples
}

\author{
O. A. Ijabadeniyi and Y. Pillay \\ Department of Biotechnology and Food Technology, Durban University of Technology, P.O. Box 1334, Durban, South Africa \\ Correspondence should be addressed to O. A. Ijabadeniyi; oluwatosini@dut.ac.za
}

Received 9 February 2017; Accepted 15 May 2017; Published 5 June 2017

Academic Editor: Gargi Dey

Copyright (C) 2017 O. A. Ijabadeniyi and Y. Pillay. This is an open access article distributed under the Creative Commons Attribution License, which permits unrestricted use, distribution, and reproduction in any medium, provided the original work is properly cited.

\begin{abstract}
Sixty household low water activity foods were examined and a simulative study was conducted in a high sugar, low $a_{w}$ almond and macadamia butter to determine the survival of Bacillus cereus and Staphylococcus aureus ATCC 25923. Results obtained from 60 low $a_{w}$ samples collected at household level had some significant differences $(P \leq 0,05)$ within food categories amongst the various tests. Spices had the highest number of aerobic bacteria, aerobic spore-formers, anaerobic spore-formers, and $S$. aureus. Mean aerobic colony counts for nuts and spices were $2.30 \mathrm{log}$ CFU/g and $4.40 \mathrm{log}$ CFU/g, respectively. Pathogens such as Escherichia coli and Cronobacter sakazakii were present in nuts, whilst Salmonella spp. was present in chocolates. This implies that certain low $a_{w}$ foods may present a public health risk. In the simulative study, temperature and high sucrose concentrations played a significant role in the survival of $B$. cereus and $S$. aureus ATCC 25923. B. cereus was found to be more osmotolerant at both reduced and elevated temperatures $\left(18^{\circ} \mathrm{C}\right.$ and $\left.25^{\circ} \mathrm{C}\right)$ in the $12 \%$ sucrose sample in both butters, whilst $S$. aureus ATCC 25923 seemed to grow better in sucrose-free samples at both temperatures in both butters. This implies that certain low $a_{w}$ foods may present a public health risk. Also, B. cereus, being a spore-forming bacterium, can be osmotolerant at both reduced and elevated temperatures.
\end{abstract}

\section{Introduction}

Food safety, is a global concern with the developing countries being the worst affected. Recently over the years, a number of incidences relating to outbreaks caused by the presence of food-borne pathogens in low water activity $\left(a_{w}\right)$ foods have increased [1]. According to Byrd-Bredbenner et al. [2], households were ranked as the most common setting and primary location in which food-borne illnesses took place in the United States. This has become a serious problem not only for food industries but also for the final consumer consuming these products.

These increased outbreaks have therefore sparked the interest and urgency to investigate and understand the possible causes of the presence of food-borne pathogens in low $a_{w}$ foods. Low $a_{w}$ foods that have drawn considerable attention to the food industries, research communities, and the public are those of spices, dry nuts, chocolates, infant and adult cereals. and milk powder, being the most common amongst many other low $a_{w}$ foods [3].
Low $a_{w}$ foods are derived from high moisture foods which are often subjected to dehydration or desiccation processes to achieve this, or they could be naturally low in moisture. Furthermore, the water content of such foods could also be achieved by adding solutes (salt or sugar) or freezing to control the quality of the final product. $a_{w}$ present in foods is a vital element in predicting the stability and safety of a food product with respect to the rate at which deterioration reactions occur [4].

Foods with low $a_{w}$ contributes to the extended shelf life of the food product which is often desirable to the consumer. However, over the years, this has led to consumer perceptions that such low $a_{w}$ foods were not of concern from a microbiological or food safety perspective and were safe for human consumption [2].

The main reason for this perception was that microorganisms were not able to thrive and proliferate in dry conditions. However, many studies done by researchers in literature have found that microorganisms have the capability of surviving in low $a_{w}$ foods $[1,5]$. The increased number of food-borne 
related illness outbreaks recently, associated with low $a_{w}$ foods, has portrayed that even though microorganisms cannot proliferate in such foods, there is a likelihood for them to be persistent for extended periods of time $[1,5,6]$. Depending on the type of microorganism, they can cause illness even with their low infectious dose or subsequent temperature abuse that permits the growth of these microorganisms [5]. Furthermore, literature has also demonstrated that Gramnegative bacteria exhibited more sensitive behaviour to low $a_{w}$ than Gram-positive bacteria. The minimum $a_{w}$ for all microbial growth is 0,60 and spoilage of foods would not be of a microbiological nature below this value [7].

The main pathogens of concern in literature were those of Salmonella spp., Escherichia coli O157:H7, Listeria monocytogenes, Cronobacter sakazakii, Staphylococcus aureus, and Clostridium botulinum $[1,8]$. A crucial step that is often omitted is an additional heating step which has the ability to control or kill potentially contaminated food-borne bacteria. Consumers often consume such foods without additional heating which is the possible cause for food-borne illness outbreaks.

Although food-borne diseases and illnesses have been on the increase in recent times, they mainly have been reported in the developed countries where food safety and quality are a priority. Rarely are such cases reported in Africa or in other developing countries and limited research has been done in Africa to combat this problem. This could be due to a lack of financial resources to conduct such research or a lack of knowledge amongst these developing communities about food safety in general.

The purpose of this study is to determine the prevalence of food-borne pathogens in household samples and to conduct a simulative study in low $a_{w}$, high sugar almond and macadamia butters. The samples collected were spices, milk chocolates, nuts, milk powder, and infant and adult cereals. The pathogens of concern in this study are those mentioned above. Since fungal growth has been widely studied in low $a_{w}$ foods, this study aims to focus on the bacterial growth in such foods. Furthermore, limited research has been done in Africa in this regard and, therefore, the purpose of this research is also to enlighten African communities about food safety of low $a_{w}$ foods.

\section{Materials and Methods}

2.1. Collection and Storage of Samples. For the first objective, commercial samples of six different categories were collected from ten Durban homes using sterile Ldpe Ziplock bags and stored at $-18^{\circ} \mathrm{C}$ to prevent the growth of bacteria. At the time of collection, the samples were collected at $25^{\circ} \mathrm{C}$. The following samples collected were as follows:

(1) Adult cereal

(2) Infant cereal

(3) Milk powder

(4) Spices

(5) Nuts

(6) Milk chocolate
For the second objective, sugar, almond, and macadamia butters were purchased from a retail food store to conduct the simulative study. These samples were stored at room temperature after the test organisms (B. cereus and S. aureus) have been confirmed to be absent in them.

2.2. Bacterial Analysis of the Samples. All the sixty samples collected were examined for the presence of L. monocytogenes, S. aureus, Salmonella spp., E. coli O157:H7, C. sakazakii, and $C$. botulinum using conventional methods. Before microbial analysis was conducted, $a_{w}$ of each sample was checked using a Novasina AG Labswift $a_{w}$ meter. Two strains were used for the simulative study on almond and macadamia butters. S. aureus ATCC 25923 was purchased from Anatech and a laboratory strain of $B$. cereus was used individually to inoculate the butters to determine its survival over a period of time in a certain sugar concentration.

\subsubsection{Conventional Methods}

C. sakazakii. $10 \mathrm{ml}$ of the macerated solution was added to $90 \mathrm{ml}$ of buffered peptone water (BPW) and was incubated at $37^{\circ} \mathrm{C}$ for 24 hours after which $1 \mathrm{ml}$ was introduced into Lauryl Sulphate Tryptose Broth and incubated at $37^{\circ} \mathrm{C}$ for 24 hours. After incubation, a loopful was streaked onto Enterobacter sakazakii Agar plates and incubated at $44^{\circ} \mathrm{C}$ for 24 hours according to the method by Nokwanda and Ijabadeniyi [9].

E. coli. A modified method by MFHPB [10] was used for this study where one gram of food sample was inoculated into $10 \mathrm{~mL}$ double strength of Lauryl Sulphate Tryptose (LST) Broth and incubated for 24 hours. After 24 hours, a $1 \mathrm{ml}$ aliquot was transferred into $10 \mathrm{ml}$ of Brilliant Green Lactose Broth (BGLB) and incubated at $35^{\circ} \mathrm{C}$ for 24 hours. After 24 hours, $1 \mathrm{ml}$ aliquot was transferred into Escherichia coli (EC) Broth tubes in a water bath at $45^{\circ} \mathrm{C}$. This was transferred into Eosin Methylene Blue (EMB) Agar, which was incubated in a water bath at $45^{\circ} \mathrm{C}$. After 24 hours, EMB plate was incubated at $35^{\circ} \mathrm{C}$ for 24 hours.

S. aureus. A dilution series was done on all samples. They were prepared using BPW. 0,1 ml of the dilution was thereafter spread-plated onto Baird-Parker Agar with egg-yolk tellurite emulsion and incubated at $35^{\circ} \mathrm{C}$ for 24 hours according to the method by ISO [11].

Salmonella. The method by SABS [12] was used for this experiment. $25 \mathrm{~g}$ of the food sample was preenriched with $225 \mathrm{ml}$ of $\mathrm{BPW}$ and was incubated at $35^{\circ} \mathrm{C}$ for 16 to 20 hours (preenriched sample). $0,1 \mathrm{ml}$ of the preenriched sample was then transferred into a test tube containing $10 \mathrm{ml}$ of Rappaport-Vassiliadis Enrichment Broth (RVB) and another $10 \mathrm{ml}$ of preenriched medium was transferred into a bottle containing $100 \mathrm{ml}$ of sterile Selenite Cystine Medium (SCM). RVB was incubated at $42^{\circ} \mathrm{C}$ for 24 hours and SCM at $35^{\circ} \mathrm{C}$ for 48 hours. The culture obtained from RVB after incubation for 24 hours and the culture obtained from SCM after incubation for 48 hours were then inoculated onto the surface of Salmonella HiCrome Agar and XLD Agar to obtain 
isolated colonies. All of these plates were incubated at $35^{\circ} \mathrm{C}$ for 24 hours and thereafter examined for growth.

L. monocytogenes. The method by Ijabadeniyi and Naidoo [13] was used for this experiment. Half-strength and fullstrength Fraser Listeria Selective Enrichment (FLSE) Broth were prepared as stipulated by the manufacturer. $1 \mathrm{ml}$ of the test sample was inoculated into $9 \mathrm{ml}$ of half-strength FLSE and incubated at $35^{\circ} \mathrm{C}$ for 24 hours. $0,1 \mathrm{ml}$ of the culture obtained in the previous step was then inoculated into a test tube containing $10 \mathrm{ml}$ of full-strength FLSE and incubated at $35^{\circ} \mathrm{C}$ for 48 hours. The culture obtained from the halfstrength FLSE incubated for 24 hours was streaked onto Oxford Listeria Selective Agar to observe growth of colonies and incubated microaerobically at $35^{\circ} \mathrm{C}$ for 24 hours. The plates were reincubated if growth was slight or if no colonies were observed for a further 24 hours. The same procedure was followed for the culture obtained from the full-strength FLSE.

Aerobic and Anaerobic Spore-Formers Count. The test sample was prepared by adding $25 \mathrm{~g}$ of sample to $225 \mathrm{ml}$ of BPW. $20 \mathrm{ml}$ of this $10^{-1}$ dilution was then pipetted into two test tubes, whereby one test tube served as a control. These two test tubes were then placed into a water bath with a thermometer placed in the control test tube. These test tubes were held at $75^{\circ} \mathrm{C}$ for 20 minutes. A dilution series was done and thereafter $0.1 \mathrm{ml}$ of the sample will be pipetted into Petri dishes and pour-plated with Trypticase Soy Agar. Both aerobic and anaerobic plates will be incubated at $35^{\circ} \mathrm{C}$ for 48 hours. The anaerobic plates will be placed into anaerobic jars with Anaerocult according to the method of MFLP [14].

Aerobic Colony Count. The test sample was prepared in the same way that they were prepared for aerobic and anaerobic spore-formers count. A tenfold dilution series was done in duplicate. $0,1 \mathrm{ml}$ of the dilutions was spread-plated onto Nutrient Agar and incubated for $37^{\circ} \mathrm{C}$ for 24 hours according to the method of ISO [15].

\subsubsection{Simulative Study}

Preparation of Inoculum. A modified method by Nummer et al. [16] was used. Two strains were used for this simulative study: a laboratory strain of B. cereus and S. aureus ATCC 25923. B. cereus cells were received as a lawn of cells on TSA and S. aureus ATCC 25923, which was received in the form of a swab, was swabbed directly onto Baird-Parker Agar. BairdParker Agar plates were incubated at $37^{\circ} \mathrm{C}$ for 24 hours. After incubation, the cells from the respective plates were washed with $5 \mathrm{ml}$ nutrient broth and were transferred into $15 \mathrm{ml}$ centrifuge tubes. A pellet was obtained by centrifugation at $2200 \mathrm{~g}$ for 10 minutes. The pellets were then resuspended into $1 \mathrm{ml}$ nutrient broth and this was used to inoculate the butters.

Inoculation of the Butters. Almond and macadamia butters were separated into $25 \mathrm{~g}$ samples. Sucrose was added to added in $3 \mathrm{~g}$ and $5 \mathrm{~g}$ quantities into the $25 \mathrm{~g}$ samples of almond and macadamia butter and mixed thoroughly. $a_{w}$ of the samples were taken before the two strains were
TABLE 1: Average water activities for the low $a_{w}$ food samples collected from households.

\begin{tabular}{lc}
\hline Food category & Average $a_{w}$ \\
\hline Infant cereal & 0,352 \\
Adult cereal & 0,381 \\
Milk powder & 0,284 \\
Nuts & 0,648 \\
Spices & 0,437 \\
\hline Chocolates & 0,427 \\
\hline
\end{tabular}

individually inoculated. $1 \mathrm{ml}$ of the two strains, $S$. aureus ATCC 25923 and B. cereus, were individually inoculated into each butter sample aseptically. The concentration of the cells of both strains was approximately $1,3 \times 10^{7} \mathrm{CFU} / \mathrm{ml}$, which is approximately $7 \log \mathrm{CFU} / \mathrm{ml}$ which was compared to a $0,5 \mathrm{McFarland}$ standard for approximate turbidity using the method by [13].

Recovery and Enumeration of S. aureus ATCC 25923 and $B$. cereus. The inoculated almond and macadamia butter samples (25 g) were assayed for S. aureus ATCC 25923 and B. cereus in duplicate at $1,7,14,21$, and 28 days, respectively. These samples were stored at $18^{\circ} \mathrm{C}$ to $20^{\circ} \mathrm{C}$ and at $25^{\circ} \mathrm{C}$. Serial dilutions were done whereby $1 \mathrm{~g}$ of all samples was transferred into $9 \mathrm{ml}$ of nutrient broth and the method by ISO [11] was used to recover and enumerate S. aureus ATCC 25923 and the method by MFLP [14] was used to recover and enumerate $B$. cereus.

2.3. Statistical Analysis. One-Way Analysis of Variables (ANOVA) and Tukey's comparison test were done to determine if there were significant differences $(P \leq 0,05)$ between the household samples as well as to compare the mean values for the simulative study.

\section{Results and Discussion}

The average $a_{w}$ per food category was calculated and is depicted in Table 1. Table 2 shows the results achieved from the first objective which was to assess the quality of low $a_{w}$ foods collected from Durban households.

Based on these average $a_{w}$ readings (refer to Table 1), all of the samples were found to have had $a_{w}$ below $0,7 . a_{w}$ for samples such as nuts $(0,648)$ and spices $(0,437)$ corresponds with the values from literature in which such samples had $a_{w}$ of $<0,6$ [3]. Infant cereal $(0,352)$, adult cereal $(0,381)$, and milk powder $(0,284) a_{w}$ values also corresponded with values in the literature by $[1,17]$.

The samples were stored in clean air-tight containers prior to collection. Furthermore, upon collection, the food was of good quality, whereby no visible fungi or mould was present. Furthermore, all samples were still within their shelf life. As per the results obtained from household samples collected, as seen in Table 2, most of the samples had low counts. Spices had the highest counts of aerobic bacteria, aerobic sporeformers, anaerobic spore-formers, and $S$. aureus followed by nuts. This could be due to poor hygiene practices in industry 
TABLE 2: Microbiological quality of low $a_{w}$ activity food presented in means of ACC, ASF, AnSF, and S. aureus (Log CFU/g) collected at household level.

\begin{tabular}{|c|c|c|c|c|}
\hline Category & $\begin{array}{c}\text { ACC } \\
(\log C F U / g)\end{array}$ & $\begin{array}{c}\text { ASF } \\
(\log \mathrm{CFU} / g)\end{array}$ & $\begin{array}{c}\text { AnSF } \\
(\log \mathrm{CFU} / \mathrm{g})\end{array}$ & $\begin{array}{c}\text { S. aureus } \\
\text { (Log CFU/g) }\end{array}$ \\
\hline Infant cereal & $2,022^{a} \pm 0,83$ & $1,90^{\mathrm{ab}} \pm 0,76$ & $0,19^{c} \pm 0,31$ & $0,30^{\mathrm{cd}} \pm 0,34$ \\
\hline Adult cereal & $1,00^{\mathrm{a}} \pm 0,77$ & $\mathrm{ND}^{\mathrm{b}}$ & $\mathrm{ND}^{\mathrm{bc}}$ & $0,19^{\mathrm{bcd}} \pm 0,25$ \\
\hline Milk powder & $1,30^{\mathrm{a}} \pm 0,72$ & $0,092^{\mathrm{b}} \pm 0,29$ & $0,096^{\mathrm{bc}} \pm 0,30$ & $0,15^{\mathrm{bcd}} \pm 0,29$ \\
\hline Nuts & $2,30^{\mathrm{a}} \pm 2,10$ & $0.66^{\mathrm{abcd}} \pm 1,40$ & $0,97^{\mathrm{abcd}} \pm 2,10$ & $0,37^{\mathrm{d}} \pm 1,20$ \\
\hline Spices & $4,40^{\mathrm{a}} \pm 0,33$ & $3,30^{\mathrm{b}} \pm 0,40$ & $2,70^{b c} \pm 1,00$ & $1,30^{\mathrm{d}} \pm 1,10$ \\
\hline Chocolates & $0,74^{\mathrm{a}} \pm 0,33$ & $0,07^{\mathrm{b}} \pm 0,23$ & $0,065^{\mathrm{bc}} \pm 0,21$ & $0,024^{\text {bcd }} \pm 0,075$ \\
\hline
\end{tabular}

(1) Results represented as Means \pm Standard Deviation. (2) Means $(n=60)$. (3) Means with same superscript letters in rows are not significantly different $(P \geq$ 0,05). (4) ACC: aerobic colony count; ASF: aerobic spore-formers count; AnSF: anaerobic spore-formers count; ND: not detected.

and prolonged exposure to air. Furthermore, spices and nuts originate from natural sources and could also have been contaminated from the natural environment as mentioned in the literature $[1,3]$.

There was no growth detected for aerobic and anaerobic spore-formers counts in adult cereal, indicating that these samples were well kept at household level and were not exposed to the air for prolonged periods of time. Infant cereal and milk powder exhibited a similar trend with regard to their colony counts indicating that there were no significant differences $(P>0,05)$ between these two samples. Most of the food categories apart from spices and nuts had relatively low colony counts amongst ACC, ASF, AnSF, and S. aureus. Chocolate samples compared to the other five food categories had the least colony counts. Whilst significant differences $(P<0,05)$ were noted amongst the different colony counts within a food category, spices and nuts were the only two categories that differed significantly from the rest of the categories in this regard.

Foods such as infant cereal, adult cereal, and milk powder have been desiccated to achieve to their desired organoleptic properties. According to [17], desiccation in turn increases the concentration of solutes in the remaining water available. The osmotic potential of water is increased by the addition of solutes. Whilst cereals contain added sugar (usually in the form of sucrose), the patterns of effect on microbial responses have exhibited similar qualities when $\mathrm{KCl}, \mathrm{NaCl}$, sucrose, and glucose were used. Glycerol as a humectant on the other hand permitted growth at lower $a_{w}$, although there were exceptions: S. aureus, for example, was more inhibited by glycerol than $\mathrm{NaCl}$.

Presence and absence tests for pathogens such as $C$. sakazakii, E. coli, L. monocytogenes, and Salmonella spp. were also conducted on the collected household samples.

Whilst C. sakazakii, E. coli, L. monocytogenes, and Salmonella spp. were not recovered from infant cereals, adult cereals, milk powder, and spices. Nut samples had $C$. sakazakii and E. coli which were found in $60 \%$ and $100 \%$ of the samples, respectively. Chocolates, on the other hand, had Salmonella present in all $(100 \%)$ of the samples $[1,8]$.

According to [7, 17], Gram-negative bacteria are more susceptible to low $a_{w}$ foods than Gram-positive bacteria. Whilst Gram-negative bacteria can only survive in foods with $a_{w} \gtrsim 0,95$, Gram-positive bacteria, on the other hand, can withstand $a_{w}$ in foods as low as $<0,8$. However, in the present study, C. sakazakii, E. coli, and Salmonella which are Gram-negative pathogens survived in low $a_{w}$ foods being nuts and chocolates which had an average $a_{w}$ of 0,648 and 0,427 , respectively, which is well below the limit as stipulated in th literature. Gram-positive bacteria like L. monocytogenes was absent in these samples. Aerobic spore-formers like $B$. cereus and anaerobic spore-formers like C. botulinum are Gram-positive bacteria that also survived in low $a_{w}$ foods in the present study. A study done by Doyle and Glass [18] showed the prevalence of C. botulinum in dried dairy products. This could be due to the presence of spores that these bacteria possess since they are spore-forming bacteria and, by having the presence of spores, would enhance their survival in stressed environments. According to Beuchat et al. [1], such bacteria survive at $a_{w}$ ranging between 0,93 and 0,92. $a_{w}$ of the foods in the present study were significantly lower that the values stipulated in the literature implying that Gram-positive aerobic and anaerobic spore-formers like $B$. cereus and $C$. botulinum have the ability to survive in foods that possess $a_{w}$ lower than this range as seen in Table 1 .

It would be highly acceptable to have an absence of pathogens in food samples such as infant and adult cereals and milk powder, due to the desiccation process that they undergo as well as spices being a naturally occurring low $a_{w}$ food that is high in antioxidants, therefore possessing high antimicrobial activity [9]. Although these pathogens of importance were absent in these samples in the present study, according to review articles and studies conducted by $[1,3,9]$, pathogens such as $C$. sakazakii were found to be present in foods such as spices and powdered infant formula and E. coli was found to be present in infant rice cereal.

Tables 3-6 represent the results obtained from the second objective which was a simulative study that was conducted on two different butters, almond and macadamia butter with an adjusted sugar content, stored at two different temperatures $\left(18^{\circ} \mathrm{C}\right.$ and at $\left.25^{\circ} \mathrm{C}\right)$ for a period of 28 days.

The almond butter used for this simulative study contained no added sugar or salt. Although there were significant differences amongst the groups within pathogen for both $S$. aureus ATCC 25923 and B. cereus (refer to Table 3), it was noted that the growth of S. aureus ATCC 25923 at $18^{\circ} \mathrm{C}$ to 
TABLE 3: Populations of S. aureus ATCC 25923 and B. cereus in almond butter at varying concentrations of sugar stored at $18^{\circ} \mathrm{C}$.

\begin{tabular}{|c|c|c|c|c|c|}
\hline \multirow{2}{*}{ Concentration of sucrose at $18^{\circ} \mathrm{C}$ to $20^{\circ} \mathrm{C}$} & \multicolumn{5}{|c|}{ Populations (Log CFU/g) over storage time (days) } \\
\hline & 1 & 7 & 14 & 21 & 28 \\
\hline \multicolumn{6}{|l|}{ S. aureus ATCC 25923} \\
\hline $0 \%$ & $5,34^{\mathrm{a}}$ & $5,25^{\mathrm{ab}}$ & $5,23^{\mathrm{abc}}$ & $4,73^{\mathrm{d}}$ & $3,59^{\mathrm{e}}$ \\
\hline $12 \%$ & $5,033^{\mathrm{ns}}$ & $4,32^{\mathrm{ns}}$ & $2,72^{\mathrm{ns}}$ & ND & ND \\
\hline $20 \%$ & $4,72^{\mathrm{a}}$ & ND & ND & ND & ND \\
\hline \multicolumn{6}{|l|}{ B. cereus } \\
\hline $0 \%$ & $5,033^{\mathrm{a}}$ & $4,74^{\mathrm{b}}$ & $4,53^{\mathrm{c}}$ & $\mathrm{ND}$ & $\mathrm{ND}$ \\
\hline $12 \%$ & $4,56^{\mathrm{ns}}$ & $4,14^{\mathrm{ns}}$ & $3,45^{\mathrm{ns}}$ & $3,30^{\mathrm{ns}}$ & $3,00^{\mathrm{ns}}$ \\
\hline $20 \%$ & $3,17^{\mathrm{a}}$ & $2,88^{\mathrm{b}}$ & $\mathrm{ND}$ & ND & ND \\
\hline
\end{tabular}

(1) Means with same superscript letters in rows within pathogen are not significantly different $(P \geq 0.05)$. (2) Means $(n=2)$. (3) ND: not detected; ns: no significance.

TABLE 4: Populations of S. aureus ATCC 25923 and B. cereus in macadamia butter at varying concentrations of sugar stored at $18^{\circ} \mathrm{C}$.

\begin{tabular}{|c|c|c|c|c|c|}
\hline \multirow{2}{*}{ Concentration of sucrose at $18^{\circ} \mathrm{C}$} & \multicolumn{5}{|c|}{ Populations (Log CFU/g) over storage time (days) } \\
\hline & 1 & 7 & 14 & 21 & 28 \\
\hline \multicolumn{6}{|l|}{ S. aureus ATCC 25923} \\
\hline $0 \%$ & $5,29^{\mathrm{a}}$ & $4,94^{\mathrm{ab}}$ & $4,51^{\mathrm{bc}}$ & $3,92^{\mathrm{d}}$ & $3,45^{\mathrm{e}}$ \\
\hline $12 \%$ & $4,74^{\mathrm{a}}$ & $4,31^{\mathrm{b}}$ & $4,029^{\mathrm{c}}$ & ND & $\mathrm{ND}$ \\
\hline $20 \%$ & $4,61^{\mathrm{a}}$ & $\mathrm{ND}$ & ND & ND & ND \\
\hline \multicolumn{6}{|l|}{ B. cereus } \\
\hline $0 \%$ & $4,29^{\mathrm{a}}$ & $3,94^{\mathrm{ab}}$ & $2,24^{c}$ & ND & ND \\
\hline $12 \%$ & $5,053^{\mathrm{a}}$ & $5,021^{\mathrm{ab}}$ & $4,86^{\mathrm{c}}$ & $4,40^{\mathrm{d}}$ & 4,30 \\
\hline $20 \%$ & $3,64^{\mathrm{a}}$ & ND & ND & ND & ND \\
\hline
\end{tabular}

(1) Means with same superscript letters in rows within pathogen are not significantly different $(P \geq 0.05)$. (2) Means $(n=2)$. (3) ND: not detected; ns: no significance.

TABLE 5: Populations of S. aureus ATCC 25923 and B. cereus in almond butter at varying concentrations of sucrose stored at $25^{\circ} \mathrm{C}$.

\begin{tabular}{|c|c|c|c|c|c|}
\hline \multirow{2}{*}{ Concentration of sucrose at $25^{\circ} \mathrm{C}$} & \multicolumn{5}{|c|}{ Populations (Log CFU/g) over storage time (days) } \\
\hline & 1 & 7 & 14 & 21 & 28 \\
\hline \multicolumn{6}{|l|}{ S. aureus ATCC 25923} \\
\hline $0 \%$ & $5,40^{\mathrm{a}}$ & $5,39^{\mathrm{ab}}$ & $5,22^{\mathrm{c}}$ & $4,87^{\mathrm{d}}$ & $4,53^{\mathrm{e}}$ \\
\hline $12 \%$ & $5,074^{\mathrm{a}}$ & $4,93^{\mathrm{b}}$ & $4,63^{\mathrm{c}}$ & $4,56^{\mathrm{cd}}$ & $4,00^{\mathrm{e}}$ \\
\hline $20 \%$ & $4,89^{\mathrm{a}}$ & $4,79^{\mathrm{ab}}$ & $4,65^{\mathrm{abc}}$ & $4,49^{\mathrm{bd}}$ & $3,15^{\mathrm{de}}$ \\
\hline \multicolumn{6}{|l|}{ B. cereus } \\
\hline $0 \%$ & $4,88^{\mathrm{a}}$ & $4,77^{\mathrm{b}}$ & $4,51^{\mathrm{c}}$ & ND & ND \\
\hline $12 \%$ & $5,25^{\text {ns }}$ & $5,22^{\text {ns }}$ & $5,041^{\mathrm{ns}}$ & $3,77^{\mathrm{ns}}$ & $3,53^{\text {ns }}$ \\
\hline $20 \%$ & $4,80^{\mathrm{ns}}$ & $4,76^{\mathrm{ns}}$ & $4,72^{\mathrm{ns}}$ & $3,69^{\mathrm{ns}}$ & $3,22^{\text {ns }}$ \\
\hline
\end{tabular}

(1) Means with same superscript letters in rows within pathogen are not significantly different $(P \geq 0.05)$. (2) Means $(n=2)$. (3) ND: not detected; ns: no significance.

$20^{\circ} \mathrm{C}$ in almond butter did not survive as well as $B$. cereus in the $12 \%$ sucrose sample. Furthermore, both strains did not survive very well in the $20 \%$ sucrose sample, as the growth of $S$. aureus ATCC 25923 had ceased by the 7th day and B. cereus by the 14 th day. However, S. aureus ATCC 25923 survived very well in a sucrose-free medium, whilst $B$. cereus survived moderately well in a low sucrose content medium ( $12 \%$ sucrose). The growth of $B$. cereus was inhibited after the 21st day. This indicates that a high sucrose content inhibits the growth of both these bacteria at slightly lower temperatures. 
TABLE 6: Populations of S. aureus ATCC 25923 and B. cereus in macadamia butter at varying concentrations of sucrose stored at $25^{\circ} \mathrm{C}$.

\begin{tabular}{|c|c|c|c|c|c|}
\hline \multirow{2}{*}{ Concentration of sucrose at $25^{\circ} \mathrm{C}$} & \multicolumn{5}{|c|}{ Populations (Log CFU/g) over storage time (days) } \\
\hline & 1 & 7 & 14 & 21 & 28 \\
\hline \multicolumn{6}{|l|}{ S. aureus ATCC 25923} \\
\hline $0 \%$ & $5,34^{\mathrm{a}}$ & $5,32^{\mathrm{ab}}$ & $4,59^{\mathrm{c}}$ & $4,47^{\mathrm{d}}$ & $4,38^{\text {de }}$ \\
\hline $12 \%$ & $5,00^{\mathrm{a}}$ & $4,99^{\mathrm{ab}}$ & $4,85^{\mathrm{abc}}$ & $4,67^{\mathrm{abcd}}$ & $3,15^{\mathrm{e}}$ \\
\hline $20 \%$ & $3,97^{\mathrm{a}}$ & $3,67^{\mathrm{b}}$ & $3,00^{\mathrm{c}}$ & ND & $\mathrm{ND}$ \\
\hline \multicolumn{6}{|l|}{ B. cereus } \\
\hline $0 \%$ & $5,39^{\mathrm{a}}$ & $5,066^{\mathrm{b}}$ & ND & ND & $\mathrm{ND}$ \\
\hline $12 \%$ & $5,18^{\mathrm{a}}$ & $4,67^{\mathrm{b}}$ & $4,66^{\mathrm{bc}}$ & $4,19^{\mathrm{d}}$ & $3,45^{\mathrm{e}}$ \\
\hline $20 \%$ & $4,20^{\mathrm{a}}$ & $3,88^{\mathrm{b}}$ & $3,72^{\mathrm{c}}$ & $3,60^{\mathrm{d}}$ & $3,49^{\mathrm{e}}$ \\
\hline
\end{tabular}

(1) Means with same superscript letters in rows within pathogen are not significantly different $(P \geq 0.05)$. (2) Means $(n=2)$. (3) ND: not detected; ns: no significance.

Whilst limited studies implicate the presence of $B$. cereus and $S$. aureus, several have implicated the presence of $E$. coli and Salmonella $[1,8,16,19,20]$

The macadamia butter used in this simulative study had a carbohydrate content of $5 \mathrm{~g}$ of which of total sugar amounted to $3,3 \mathrm{~g}$ per $100 \mathrm{~g}(3,3 \%)$. A similar trend was noticed in macadamia butter stored at $18^{\circ} \mathrm{C}$ despite the butter having the contained added sugar. S. aureus ATCC 25923 grew well in the sucrose-free sample (0\%) but, because of the butter already containing 3,3\% sucrose, it can be deduced that $S$. aureus did not survive after 14 days at very low sucrose contents. B. cereus, on the other hand, survived after 14 days but ceased to grow after the 21st day in a very low sucrose medium indicating that $B$. cereus is more osmotolerant than $S$. aureus ATCC 25923. Furthermore, like almond butter, $B$. cereus grew fairly well in the $12 \%$ sugar sample. This is, in addition to the 3,3\% sucrose that butter had already contained, implying that $B$. cereus grows moderately well in $12-18 \%$ sucrose medium. Both strains of bacteria did not survive very well at $20 \%$ sucrose content, implying that a high sucrose content would inhibit their growth.

Temperature seemed to have significantly influenced the growth of both bacteria. It was observed that the growth of S. aureus ATCC 25923 had grown fairly well in both the $12 \%$ and $20 \%$ sucrose samples. The growth of B. cereus had ceased after the 21 st day in the sucrose-free (0\%) sample but was now able to thrive in the $20 \%$ sucrose sample, implying that $B$. cereus is more osmotolerant compared to $S$. aureus ATCC 25923. However, at $25^{\circ} \mathrm{C}, \mathrm{S}$. aureus ATCC 25923 was able to metabolise sucrose as a carbon source than it did at a reduced temperature.

A similar trend was noticed in macadamia butter stored at $25^{\circ} \mathrm{C}$. It was observed that the growth of $\mathrm{S}$. aureus ATCC 25923 was inhibited after the 21 st day in the $20 \%$ sucrose sample, whilst the growth of $B$. cereus ceased after the 7 th day in the $0 \%$ sucrose sample. However, B. cereus grew fairly well throughout the 28 days in both the $12 \%$ and $20 \%$ sucrose samples.

From this simulative study, it can be deduced that the concentration of sugars (sucrose) and the effect of temperature affected the growth of both strains of bacteria.
Whilst S. aureus ATCC 25923 was able to thrive in a sample that was sucrose-free $(0 \%), B$. cereus proved to be more osmotolerant surviving in the $12 \%$ sucrose concentration at reduced temperatures $\left(18^{\circ} \mathrm{C}\right.$ to $\left.20^{\circ} \mathrm{C}\right)$. Both strains did not survive very well at $20 \%$ sucrose concentration at reduced temperatures. At an elevated temperature $\left(25^{\circ} \mathrm{C}\right)$, both $B$. cereus and S. aureus ATCC 25923 were able to grow at all three concentrations of sucrose in almond butter. There were no significant differences between the growth of both bacteria in both types of butter, except for $20 \%$ sucrose concentration in almond butter.

According to Finn et al. [5], bacteria have osmoprotectants which aid in bacterial survival in low $a_{w}$ environments. The function of osmoprotectants is to balance the osmolarity within the bacterial cell to that of the external environment to avoid any loss of water.

In this present study, temperature and humectants (sucrose) induced a stressed environment for the bacteria to grow. According to Carlin et al. [21], despite the optimum growth limits for bacteria to thrive, bacteria have to adjust to changes in temperature. Mechanisms of modification to their lower or higher temperature growth limits show significant differences.

There could be a high possibility that, due the sporeforming ability of $B$. cereus in an unfavourable environment, the vegetative cell itself is protected from the stressed environment as opposed to $S$. aureus which is not a spore-forming bacterium and is more susceptible to stressed environments. Due to the fact that $a_{w}$ of the nut butter has increased after sucrose was added, it would be possible for both strains of bacteria to survive. Carbon as a source of nutrition also plays a vital role, when present in low concentrations.

\section{Conclusion}

From this study, it can be concluded that low $a_{w}$ food samples possessed low colony counts except, for spices and nuts which had the highest colony counts as well as aerobic sporeformers, anaerobic spore-formers, and S. aureus compared to the other food categories. Overall, good manufacturing practices should be followed in industry and in the home 
to avoid outbreaks of food-borne illness. Future work can be conducted on fungi producing mycotoxins, which have been in the spotlight in recent years; furthermore since fungal growth has been highly associated in low $a_{w}$ foods, it would be apt to conduct such work.

\section{Disclosure}

This work has been accepted for presentation at IAFP 2017 Annual Meeting in Florida, USA.

\section{Conflicts of Interest}

The authors declare that there are no conflicts of interest regarding the publication of this paper.

\section{Acknowledgments}

This work is based on the research supported in part by the National Research Foundation of South Africa, Unique Grant no. 93977.

\section{References}

[1] L. R. Beuchat, E. Komitopoulou, H. Beckers et al., "Low-water activity foods: increased concern as vehicles of foodborne pathogens," Journal of Food Protection, vol. 76, no. 1, pp. 150172, 2013.

[2] C. Byrd-bredbenner, B.-B. Carol, B. Jacqueline, Jennifer M.-B., and Q. Virginia, "Food safety in home kitchens: a synthesis of the literature," International Journal of Environmental Research and Public Health, vol. 10, no. 9, pp. 4060-4085, 2013.

[3] R. M. Syamaladevi, J. Tang, R. Villa-Rojas, S. Sablani, B. Carter, and G. Campbell, "Influence of water activity on thermal resistance of microorganisms in low-moisture foods: a review," Comprehensive Reviews in Food Science and Food Safety, vol. 15, no. 2, pp. 353-370, 2016.

[4] V. A. Vaclavik and E. W. Christian, Essentials of Food Science, Springer, New York, NY, USA, 2008.

[5] S. Finn, O. Condell, P. McClure, A. Amézquita, and S. Fanning, "Mechanisms of survival, responses, and sources of Salmonella in low-moisture environments," Frontiers in Microbiology, vol. 4, article 331, pp. 1-15, 2013.

[6] V. N. Scott, Y. Chen, T. A. Freier et al., "Control of salmonella in low-moisture foods I: minimizing entry of salmonella into a processing facility," Food Protection Trends, vol. 29, pp. 3542353, 2009.

[7] O. Erkmen and T. F. Bozoglu, Food Microbiology: Principles into Practice, Wiley-Blackwell, 2016.

[8] L. Beuchat, E. Komitopoulou, R. P. Betts et al., "Persistence and survival of pathogens in dry foods and dry food processing environments," Tech. Rep., ILSI Europe, 2011.

[9] M. Nokwanda and O. A. Ijabadeniyi, "Food borne bacteria isolated from spices and fate of Cronobacter sakazakii ATCC 29544 in black pepper exposed to drying and various temperature conditions," Journal of Food, Agriculture and Environment, vol. 11, no. 3-4, pp. 492-495, 2013.

[10] MFHPB, MFHPB-19 Enumeration of Coliforms, Feacal Coliforms and of E. coli in Foods Using the MPN Method, Microbiology Food Health Protection, 2002.
[11] ISO, "Microbiology of food and animal feeding stuffs. Horizontal method for the enumeration of coagulase-positive staphylococci Staphylococcus aureus and other speciesI," in Technique Using The Baird-Parker Agar Medium, International Organisation for Standardization, Geneva, Switzerland.

[12] SABS, Salmonella-SABS-6579 Microbiology: General Guidance on Methods for The Detection of Salmonella, SABS, 2003.

[13] O. A. Ijabadeniyi and S. Naidoo, "Biocontrol of Listeria monocytogenes ATCC 7644 in fresh tomato with probiotics," Journal of Pure and Applied Microbiology, vol. 8, no. 5, pp. 3973-3980, 2014.

[14] MFLP, MFLP-44 Determination of Aerobic and Anaerobic Sporeformers, Microbiology Food Laboratory Procedure, 2012.

[15] ISO, "Microbiology of the food chain-horizontal method for the enumeration of microorganisms," in Colony Count at 30 Degrees $C$ by The Surface Plating Technique, International Organisation for Standardization, Geneva, Switzerland.

[16] B. A. Nummer, S. Shrestha, and J. V. Smith, "Survival of Salmonella in a high sugar, low water-activity, peanut butter flavored candy fondant," Food Control, vol. 27, no. 1, pp. 184-187, 2012.

[17] T. Ross and D. S. Nichols, "ECology of Bacteria and Fungi in Foods - Influence of Available Water A2-Batt," in Encyclopedia of Food Microbiology, A. Carl and M. L. Tortorello, Eds., Oxford: Academic Press, 2nd edition, 2014.

[18] M. E. Doyle and K. Glass, Spores of Clostridium Botulinum in Dried Dairy Products, Food Research Institute, 2013.

[19] T. Blessington, E. J. Mitcham, and L. J. Harris, "Survival of Salmonella enterica, Escherichia coli O157:H7, and listeria monocytogenes on inoculated walnut kernels during storage," Journal of Food Protection, vol. 75, no. 2, pp. 245-254, 2012.

[20] M. A. Kimber, H. Kaur, L. Wang, M. D. Danyluk, and L. J. Harris, "Survival of salmonella, escherichia coli O157:H7, and listeria monocytogenes on inoculated almonds and pistachios stored at -19, 4, and 24.C," Journal of Food Protection, vol. 75, no. 8, pp. 1394-1403, 2012.

[21] F. Carlin, J. Brillard, V. Broussolle et al., "Adaptation of Bacillus cereus, an ubiquitous worldwide-distributed foodborne pathogen, to a changing environment," Food Research International, vol. 43, no. 7, pp. 1885-1894, 2010. 

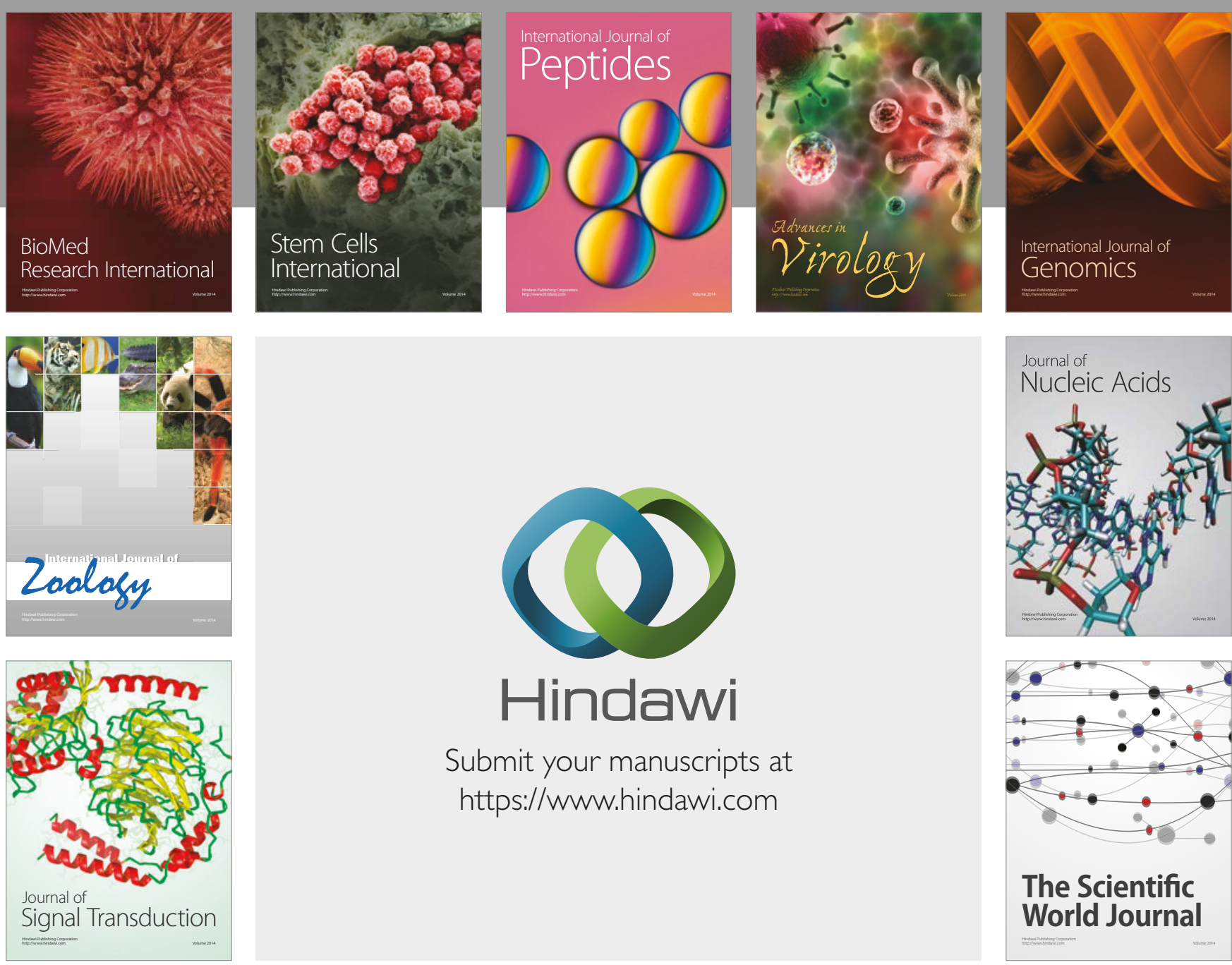

Submit your manuscripts at

https://www.hindawi.com
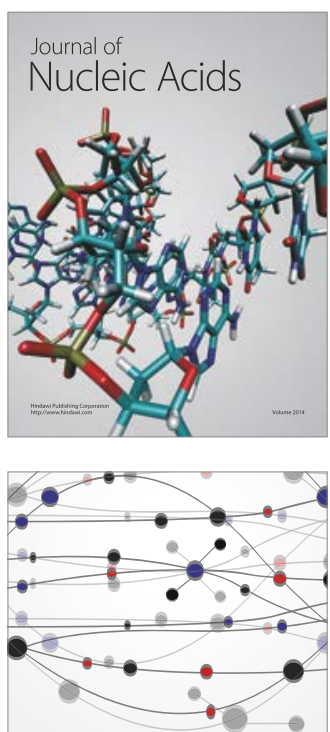

The Scientific World Journal

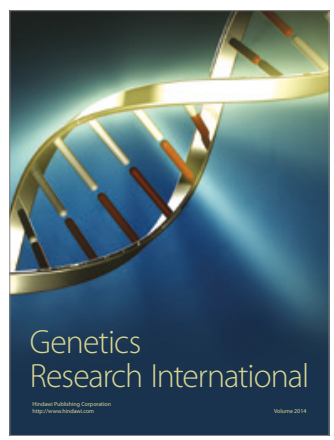

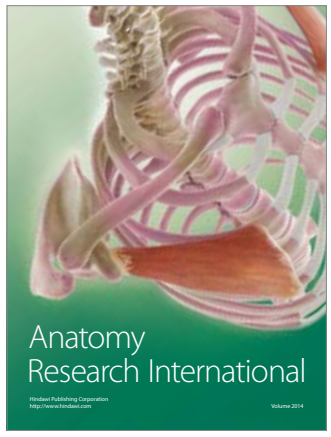

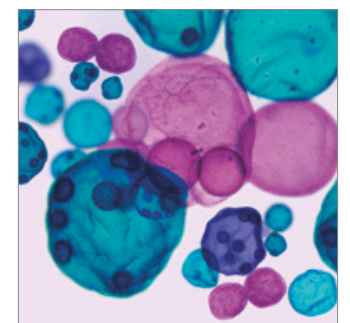

International Journal of Microbiology
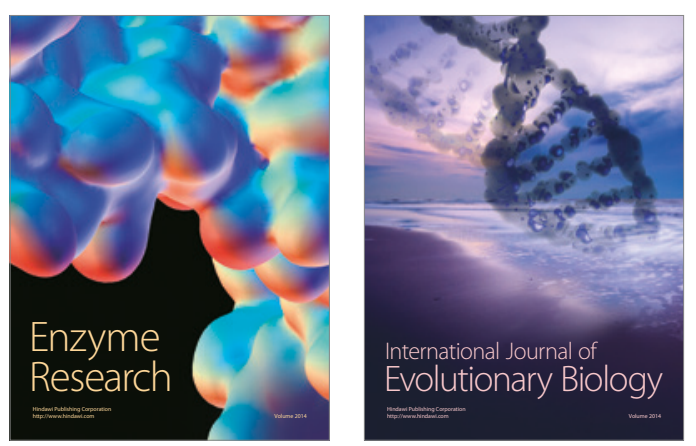
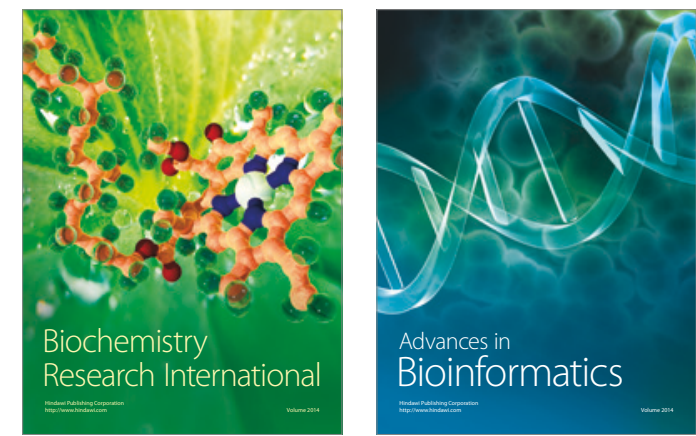

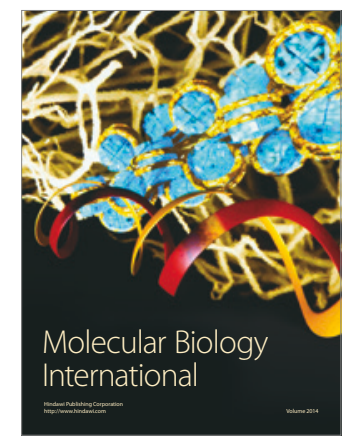

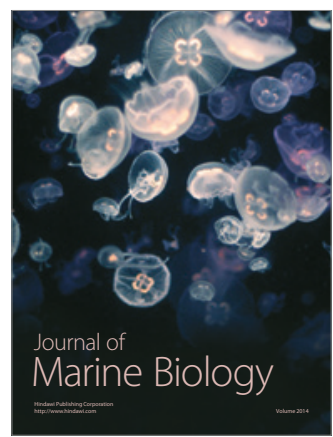

